\title{
CORPO-MÁQUINA: DIÁLOGOS ENTRE DISCURSOS CIENTÍFICOS E A GINÁSTICA
}

\author{
MACHINE-BODY: DIALOGUES BETWEEN SCIENTIFIC DISCOURSE AND \\ GYMNASTICS
}

\section{CUERPO-MÁQUINA: DIÁLOGOS ENTRE DISCURSOS CIENTÍFICOS Y LA GIMNASIA}

\author{
Edivaldo Góis Junior*, Carmen Lúcia Soares*, Vinícius Demarchi Silva Terra*
}

\begin{abstract}
Palavras chave: Corpo humano.

História.

Ciência.

Ginástica.

Resumo: Este artigo objetivou a descrição de discursos científicos e práticas modernas sobre o corpo em um recorte temporal delimitado pelo século XIX e virada do século $X X$, identificando a consolidação da representação de corpo-máquina como fonte de inspiração para outras práticas, como a literatura, a fotografia e, principalmente, a ginástica, no contexto da produção cultural europeia. Teve como fontes os discursos de Claude Bernard e Georges Demeny. Concluiu, ao analisar esses discursos, que a metáfora do corpo-máquina influenciou a ginástica, que, para se justificar como prática, nos termos de Demeny, evoluiu para sua fase positiva.
\end{abstract}

Keywords:

Human Body.

History.

Science.

Gymnastics.

Palabras clave: Cuerpo humano. Historia.

Ciencia.

Gimnasia.

\begin{abstract}
This article aimed to describe scientific discourse and modern practices about the body in the nineteenth century and the turn of the twentieth century, identifying the consolidation of the machine-body representation as influential in other practices such as literature, photography, and especially gymnastics in the context of European cultural production. Its sources were discourses of Claude Bernard and Georges Demeny. After analyzing those discourses, it concluded that the machine-body metaphor influenced gymnastics, which, in order to justify itself as a practice, in the Demeny's words, evolved to its positive phase.
\end{abstract}

Resumen: Este artículo tiene como objetivo describir discursos científicos y prácticas modernas sobre el cuerpo en el siglo XIX y comienzos del siglo XX, identificando la consolidación de la representación del cuerpo-máquina como fuente de inspiración para otras prácticas, como la literatura, la fotografía y, en especial, la gimnasia, en el contexto de la producción cultural europea. Se utilizaron como fuentes los discursos de Claude Bernard y Georges Demeny. El estudio concluyó, al analizar estos discursos, que la metáfora del cuerpo-máquina influyó en la gimnasia que, para justificarse como práctica, en los términos de Demeny, evolucionó hacia su fase positiva.
*Universidade Estadual de Campinas (UNICAMP). Campinas, SP, Brasil. E-mail: egoisjunior@gmail.com

**Universidade Federal de São Paulo (UNIFESP). Santos, SP. Brasil. E-mail: paraovinicius@gmail.com

Recebido em: 06-01-2015 Aprovado em: 14-06-2015 (c) (i) () Licence 


\section{INTRODUÇÃO'}

No século XIX, mais especificamente na década de $1860^{2}$, no auge da modernidade, Claude Bernard (1813-1878), no texto Introduction a l'étude de la médecine experimentale, de 1865, propôs o "método experimental", donde radica a maior parte da produção científica atual. Foi pelas promessas desta razão, forjada ao longo de três séculos, que a política se esmiuçou na vida, operada por desejos maquínicos, como discutiremos adiante.

A consagração de um modelo experimental de pesquisar o corpo é um discurso contemporâneo que se afirmou como monumento histórico na ciência, erguido sobre ruínas e dissonâncias, muitas vezes apaziguadas pela ansiedade historicista. Dada a complexidade desta história da ciência, sobretudo pelos campos de disputas e suas mudanças axiológicas, a prudência sugere que não tratemos aqui do ser da ciência, ou qualquer ontologia apriorística.

Desejamos aqui pensar nos ecos oitocentistas, nesta nítida rede de solidariedades e de intercomunicabilidade, portanto, não se afirma aqui uma ideia da história como progresso, ou, ainda, como linearidade. Pensar nos ecos oitocentistas na constituição desses conhecimentos voltados ao corpo é muito mais uma constatação da existência de suas dinâmicas constituídas de ambiguidades, de rupturas, descontinuidades e permanências que, entretanto, se tecem em tênues redes. Nessa perspectiva, nos interessa pensar em como esses discursos e práticas sobre o corpo, constitutivos da ciência, e que influenciam o campo da cultura, traduzem camadas da vida social. Daí a importância, a necessidade e mesmo o dever de pensar esses conhecimentos sobre o corpo na ciência, mergulhados em uma atmosfera mental de seu próprio tempo, fornecendo resposta a problemas de consciência que já não são exatamente os nossos, como nos diz Marc Bloch (2010).

O desenho do corpo na história se faz com traços por ele mesmo esboçados, pelas diferentes vias de se falar dele, com vestígios que, muitas vezes, não mais reconhecemos no presente. Seria, então, importante sublinhar que sua eleição como um objeto da história só muito recentemente é que recebeu status no campo das Ciências Humanas. Isso porque essa maneira de fazer história em que o corpo ganha estatuto de objeto é própria da Escola dos Analles e das fronteiras e interações que estabelecem os intelectuais que a ela se filiam, da necessidade que sugerem de aproximação com as outras Ciências Sociais, com a Educação, Filosofia, Psicanálise e a Arte. Essa compreensão é tributária de pensadores como o etnólogo Marcel Mauss, (1936) ${ }^{3}$ que, com seu clássico estudo sobre as técnicas corporais, tratou o corpo como arquivo simbólico das sociedades, dos seus modos de se educar e de viver, do habitus; de Norbert Elias (1994; 1995) e seus estudos sobre os processos civilizatórios publicados a partir de 1939, nos quais historiciza a economia psíquica a partir do aporte da Sociologia e da Psicanálise; de historiadores como Marc Bloch (1987; 2001), que na década de 1940 afirmava que era necessário farejar a carne humana e pensar os seres humanos por detrás de toda a vida social e que uma "[...] história mais digna de tal nome do que os tímidos ensaios a que nossas possibilidades nos limitam hoje teria em consideração as aventuras do corpo [...]" (2001, p. 91); de Michel Foucault (1980, 1998, 2003, 2008), que nos anos 1970 produziu inúmeros estudos sobre a centralidade no corpo na medicina, no poder sobre o corpo e sobre a

1 As citações dos textos originais em língua estrangeira foram traduzidas para o português pela autoria.

2 "We need very much a name to describe a cultivator of science in general. I should incline to call him a Scientist. Thus, we might say, that as an Artist is a Musician, Painter, or Poet, a Scientist is a Mathematician, a Physicist, or Naturalist" (WHEWELL, 1860, p. CXIII).

3 Comunicação apresentada à Société de Psychologie, em 17 de maio de 1934. 
vida, no biopoder e na biopolítica. Sem dúvida que há muitos outros pensadores que poderiam ser aqui evocados, mas os que aqui mencionamos inauguram essa delimitação de um novo objeto que aporta, então, novos problemas e interpretações. Esses autores dão legitimidade ao que afirmou a historiadora Denise Sant'Anna (1994). Segundo ela, há uma ideia geral de que as nossas atitudes, as mais banais, os nossos valores, os mais caros, as nossas intolerâncias e nossas sensibilidades, as mais singelas, são produzidas pela história e essa ideia nos auxilia na compreensão das diferenças que se operam no tempo em relação a esse conjunto de atitudes, gestos e pensamentos.

Poderíamos afirmar que é esse movimento do pensamento na história que permitiu a emergência de novos objetos, de novos problemas e de novas interpretações e pelo qual foi possível considerar e configurar o corpo como objeto de estudo da história e, sobretudo, historicizar sua própria configuração na ciência moderna.

Se o corpo é um objeto múltiplo, se ele pode representar dimensões bastante diferentes da vida, tais como a sensibilidade, a própria expressão de um indivíduo ou de um grupo social, ou, ainda, uma verdadeira mecânica ligada ao trabalho, ele evoca assim numerosas imagens, sugere múltiplas possibilidades de conhecimento, amplia territórios e horizontes da vida social e diz mais, talvez, que os indicadores de pobreza ou de abundância... (VIGARELLO, 2000, p. 299).

Neste artigo, temos como objetivo descrever alguns desses discursos em um recorte temporal delimitado pelo século XIX e virada do século XX, identificando a consolidação de uma ideia de corpo-máquina que se tornará fonte de inspiração para outras práticas, como a literatura, a fotografia e, principalmente, a ginástica no contexto da produção cultural e científica europeia.

Desse modo, compreender como o corpo foi descrito pela ciência em um recorte temporal amplo na Europa pode nos ensinar sobre as suas influências específicas e comuns. As sociedades mercantilistas que crescem economicamente reorganizando seu modo de produção no capitalismo, como a França e a Inglaterra, podem transformar ou preservar práticas corporais ancoradas em condicionantes estruturais, mas também em uma mentalidade específica.

Não pretendemos navegar em mar aberto pelas correntes turbulentas dos conceitos e categorias, mas circunscrever a nau pela costa, identificando em alguns autores e obras os bastiões dos saberes e sensibilidades oitocentistas, bastiões que têm sido usados como plataformas de defesa de determinadas práticas, impedindo assaltos de outras racionalidades situadas em meio àquelas homologadas pela ciência. Interessaram-nos particularmente, como fontes, os discursos dos fisiologistas Claude Bernard (1813-1878) e Georges Demeny (18501917). Eles propiciam aproximações e distanciamentos sobre um humano paulatinamente caracterizado como uma complexa máquina. Ao percorrer suas permanências e suas descontinuidades, observaremos suas repercussões em práticas corporais, como a ginástica.

\section{CORPO-MÁQUINA}

Um corpo máquina seria limpo, mais produtivo, moralmente eficaz. Essa representação ancora-se numa concepção econômica, sem dúvida, pois o corpo é pensado então como uma máquina que produz. A chave para entender o significado da representação do corpo na época 
de consolidação do capitalismo é pensar que, nesse modo de produção, a força de trabalho é vendida ao detentor do capital, e o corpo humano, à época, era concebido pelos governos como um bem produtor, sendo de certa forma um bem pertencente à nação, que deveria cuidar dele, daí brotando expressões como "capital humano" ou "motor humano". (RABINBACH, 1992).

Durante o século XIX, esses discursos sobre o corpo colaboraram para uma lenta difusão de práticas corporais presentes nos hábitos cotidianos, como a higiene e até mesmo em práticas artísticas, como a literatura.

Soares e Fraga (2003), por exemplo, identificam uma pedagogia dos corpos retos, avessos às deformidades no início do século XIX. Os pesquisadores utilizam a literatura do período como fonte para descrever uma representação de corpo reto, anatomicamente ereto, observando a literatura de Victor Hugo (1802-1885). Na personagem de Quasímodo, o sineiro da Notre-Dame que por sua aparência física se envergonha do olhar alheio, é descrita uma representação de negação da deformidade. A aversão à aparência de Quasímodo revela uma ideia de corpo em contraposição à personagem, ou seja, no ideal de um corpo ereto, sem deformidades.

Victor Hugo descreve o enclausuramento do corpo de Quasímodo, impedido de conviver socialmente devido a sua aparência. Assim, a deformidade devia ser omitida, escondida, exilada em asilos, prisões, sanatórios, hospitais de isolamento (SOARES; FRAGA, 2003).

Ainda no campo literário, acerca dessa presença do corpo manipulado pela ciência, havia a fascinante crença do domínio sobre a natureza, o que não impediu que a literatura resistisse a esse otimismo, lembrando-a sobre os seus limites. Exemplo disso é o romance Frankenstein; or, the Modern Prometheus de Mary Shelley, primeira edição de 1818. Esta versão moderna do mito de Prometeu ${ }^{4}$ o providente, aquele que antevê, pensa antes de agir - oferece, num certo sentido, algo do olhar e da percepção estranha e nova do ser humano pelo seu corpo no período.

A personagem de Mary Shelley, o Dr. Frankenstein, deseja realizar um projeto dentro do espírito positivo a partir da ciência, qual seja, de um homem perfeito constituído de partes isoladas, luminoso e inteiro feito de reconstituição das carnes mortas. Contudo, o controle da natureza corporal transformou-se em fracasso, pois as carnes mortas comprometeram o seu projeto positivo de criação superior e ele não pode ir além. A anatomia não foi suficiente, a análise dos processos de decomposição e apodrecimento naturais do corpo humano num certo sentido o traiu. O corpo, outrora lugar de beleza e força, torna-se muito brevemente em alimento para os vermes. Cabem aqui as palavras da personagem de Mary Shelley, o Dr. Frankenstein:

[...] Vi como a superior forma humana se degrada e se desfaz; contemplei a decomposição da morte tomar o lugar das faces rosadas da vida; vi como os vermes herdam as maravilhas dos olhos e do cérebro [...] Recolhi ossos em necrotérios, perturbei com dedos profanos os segredos tremendos do corpo humano. (SHELLEY, 1869, p.43)

Há nesta literatura a crítica a uma ciência que perscruta a vida, que não se basta pelas observações diretas dos corpos inertes típicas da anatomia concebida por Vesalius/vesaliana (TERRA, 2007). A ciência médica do século XIX desejava extrapolar o campo da observação 
e descrição, almejava agora a compreensão da vida para seu domínio. Exemplos disso são encontrados na produção científica de Claude Bernard (1813-1878), fisiologista francês que se dedicou aos estudos de medicina. Mesmo não sendo o primeiro pesquisador a dedicar-se a uma fisiologia experimental, destaca-se como o principal articulador de um método científico para as observações dos fenômenos biológicos (CAPONI, 2001).

Nesse sentido, Bernard criou os limites e especificidades da medicina experimental em relação à pesquisa médica anterior. No livro La Science expérimentale, de 1878, uma reedição ampliada do seu clássico Introduction à l'étude de La médecine expérimentale, 1865, ressaltava:

A fim de compreender a particularidade do problema fisiológico, é necessário, antes de tudo, circunscrever a fisiologia geral e mostrar que ela é uma ciência experimental e não uma ciência natural. As ciências naturais são ciências da observação ou ciências descritivas. Elas nos dão a previsão dos fenômenos, mas, elas permanecem ciências contemplativas da natureza. As ciências experimentais são ciências da experimentação, ou explicativas. Elas ultrapassam as ciências da observação que lhes servem de base e chegam a ser ciências da ação, ou seja, ciências que conquistam a natureza. (BERNARD, 1878, p. 101)

O domínio da natureza por meio da racionalidade científica, essa forma de conhecimento típica do século XIX, nutre, de maneira clara, os processos de industrialização e urbanização forjados nesse tempo e colabora para uma representação do que é moderno. Nesse sentido a objetividade da física e da química inspirava uma ciência médica disposta a esmiuçar o corpo como objeto físico, como máquina. Claude Bernard enfatizava:

Eu me proponho a demonstrar que os fenômenos dos corpos vivos são, como aqueles dos corpos inorgânicos, submetidos a um determinismo absoluto e necessário. A ciência vital não pode empregar outros métodos nem ter outras bases que aquelas da ciência física [science minérale] e não existe nenhuma diferença a estabelecer entre os princípios das ciências fisiológicas e aqueles das ciências físico-químicas. (BERNARD, 1878, p. 40)

Objeto e sujeito estão igualmente comprometidos neste projeto de racionalidade, pois assim como certas estruturas do corpo vivo serão sacrificadas pela mão do cientista a fim de descobrir suas respectivas funções falidas, seu olhar também será devidamente "armado" com aparelhos especiais para que o fenômeno possa ser percebido, de imperfeito que é, o que faz do experimento um processo de mediação entre o mundo subjetivo e o objetivo (TERRA, 2002). Essa objetividade leva Bernard a defender teoricamente que, nas ciências da vida, todo fenômeno tinha uma causa primeira que repetida nas mesmas condições reproduz o mesmo resultado em uma relação causal determinista. Como na física mecanicista, o organismo estava submetido a leis. Cabia, então, à fisiologia, apenas um caminho, o da compreensão do corpo para a sua intervenção e transformação. Bernard, em seu Rapports sur les progrès et la marche de la physiologie générale en France de 1867, indica que:

Nas ciências experimentais, onde se buscam as leis efetivas dos fenômenos, é necessário estudar as diferenças orgânicas para reconduzi-las, cada uma, às suas condições materiais elementares de manifestação. Eis aí porque eu disse relativamente às propriedades dos nervos, que buscando apagar as diferenças para tudo confundir em analogias e semelhanças, impedem-se os progressos da fisiologia geral tal qual eu a compreendo. Eu não saberia, de fato, que eu a desenvolveria mais tarde, ou seja, considerar a fisiologia geral como uma ciência destinada a permanecer na esfera contemplativa das ciências naturais, mas, bem 
mais como uma ciência experimental destinada a agir sobre os fenômenos dos seres vivos (BERNARD, 1867).

Se a física do século XIX destacava-se como base de uma mecânica que transformava o mundo com novas tecnologias, as ciências da vida não podiam estar fora deste contexto moderno, e uma das formas mais recorrentes e prósperas de atestar essa proximidade era a metáfora do corpo como máquina. Em seus termos:

A causa primeira da vida dá a evolução ou a criação da máquina organizada; mas a máquina, uma vez criada, funciona em virtude de propriedades de seus elementos constituintes e sob a influência de condições físico-químicas que sobre eles agem. Para o fisiologista e o médico experimental o organismo vivo nao é mais que uma máquina admirável, dotada de propriedades as mais maravilhosas, postas em ação com a ajuda de mecanismos os mais complexos e os mais delicados. É uma máquina na qual eles devem analisar e determinar o mecanismo, a fim de poder modificá-lo, pois a morte acidental não é mais que o deslocamento ou a destruição do organismo em consequência da ruptura ou da cessação da ação de um ou de inúmeros destes macanismos vitais (BERNARD, 1867).

A esperança de controle sobre a natureza corpórea ganha novas nuanças a partir da experimentação. A máquina, uma vez desvendada, poderia dar à ciência o poder de remediação sobre seu desfalecimento. Os anseios eram um tanto otimistas, pois não faltava crença aos seus defensores de que a objetividade do pensamento positivo, superior ao metafísico, era capaz de intervir e modificar o corpo, tornando-o mais resistente, ou ainda, de reproduzi-lo para a substituição de componentes danificados. Aplicações tangíveis no campo da medicina, mas também em práticas corporais tidas como auxiliares no projeto do corpo-máquina através de seu controle e manutenção, mais conhecida, naquela centúria, como ginástica racional.

\section{A MÁQUINA EM MOVIMENTO: DISCURSOS E PRÁTICAS SOBRE OS CORPOS}

O corpo concebido a partir de lógicas maquínicas ganha mais espaço nos discursos médicos, que, por sua vez, através de uma representação de racionalidade objetiva e científica, influenciavam a cultura moderna. A produção de Etienne-Jules Marey (1830-1904) colaborou para esse elo. Fisiologista e fotógrafo francês, ele foi pioneiro na captação dos movimentos dos corpos através da fotografia, colaborando para seu entendimento como uma máquina no campo da ciência.

Em um primeiro momento a fotografia era considerada mais uma técnica, e a ciência foi sua entusiasta pela possibilidade de captar os movimentos do corpo com mais objetividade e precisão. Foi na fisiologia que Etienne-Jules Marey se destacou desenvolvendo as técnicas de fotografia, inventando aparelhos mecânicos que auxiliavam os novos estudos do corpo no campo da termodinâmica. Um dos mais notáveis aparelhos produzidos a partir da tecnologia da fotografia por Marey foi a cronofotografia, que possibilitava captar um movimento corporal em uma única chapa fotográfica, possibilitando a análise biomecânica do movimento (TERRA, 2002).

Mais uma vez o corpo-máquina é objeto de observação empírica e agora pode ser capturado em uma estética propriamente moderna que, combinada com a análise científica e mecânica dos movimentos corporais, associava física e biologia. É contemporânea a estas representações científicas a disseminação de novas práticas corporais, certamente influenciadas por elas. Por exemplo, a ginástica na França, mediante uma lenta difusão, ganha no século 
XIX a atenção dos médicos e governantes (VIGARELLO, 2003, VIGARELLO; HOLT, 2008, SOARES, 1998). Estudos sobre o corpo revelavam a importância de seu desenvolvimento e treinamento para a manutenção da saúde individual, mas, sobretudo, da energia social (RABINBACH, 1992).

Segundo os médicos, era necessário metodizar a ginástica, torná-la contemporânea das teorias da fisiologia, que refutavam o valor do desgaste físico, defendendo uma economia e desenvolvimento da energia no treinamento (GOELLNER, 1996, SOARES, 1996). Com este objetivo, estrutura-se uma ginástica racional e científica que tem como um dos expoentes Georges Demeny (1850-1917), que foi colaborador de Marey na Station Physiologique, laboratório onde produziu a maior parte de sua obra. Se Marey aproximou a engenharia da vida, Demeny foi seu braço aplicado: biólogo e pedagogo francês (SOARES 1998, SOARES, FRAGA, 2003), era um assíduo praticante de ginástica, e se destacou nos estudos de análise dos movimentos através da invenção de uma câmera cronofotográfica (BAKER, 2007). Fundou a Sociedade de Ginástica Racional e trabalhou na Escola de Ginástica Joinville-Le-Pont. (SOARES, 1998, MELO, 2005)

Demeny dedicou-se aos estudos sobre energia e eficiência/eficácia dos movimentos, preocupando-se com os malefícios da prática desmedida de exercícios físicos sem sistematização. Importava naquele momento consolidar uma prática de ginástica sobre os auspícios das ciências físicas e biológicas, opondo-a em relação aos exercícios espontâneos. Para isso era preciso construir um discurso de alerta sobre os benefícios de uma ginástica racional e os perigos de uma ginástica não sistematizada (SOARES, 1998). No prefácio de um guia para mestres de ginástica, escrito em 1898, publicado em 1904, intitulado Guide du Maitre: chargé de l'enseignement des exercices physiques dans les écoles, ele defende:

A melhoria moral dos homens é ligada ao seu estado físico. A Educação física, em definitivo, se propõe a aumentar o rendimento de cada um no trabalho e de utilizar, da melhor forma possível, este dispêndio de energia; ela é, pois, para toda nação uma questão econômica da mais alta importância. Assim compreendido, o papel do educador é fundamental; sua tarefa se tornará menos ingrata desde que estas verdades sejam compreendidas; os homens que governam devem propagálas. Em uma sociedade bem organizada, cada um, na medida de sua sabedoria e de suas forças, tem como dever de colocar a ciência a serviço do bem comum (DEMENY, 1904a, p. 8).

Para Demeny os objetivos higiênicos dos exercícios só seriam alcançados a partir de princípios científicos, como explicitado no livro Les bases scientifiques de l'éducation physique, editado pela primeira vez em 1903 (DEMENY, 1931). Para isso, cabia aos seus defensores organizar a ginástica como uma prática sistematizada, unificando seus princípios, e reivindicando uma intervenção do Estado traduzida no investimento público na organização de ginásios e em sua disseminação nas escolas (GLEYSE et al., 2002). Central neste discurso era a valorização da ginástica como uma prática de cuidado com os corpos utilizando a metáfora das máquinas. Demeny, no texto Mécanisme et education dus mouviments, de 1904, escreve:

Nosso corpo é submetido às mesmas leis que as máquinas ordinárias; os movimentos dos membros, o deslocamento do corpo em massa são decorrentes da ação de forças interiores ou exteriores.

As primeiras têm sua origem nos músculos, mudam a forma do nosso corpo e as posições relativas aos ossos; são as contrações e a tonicidade muscular, a elasticidade e a resistência de nossos tecidos. 
As segundas forças são exteriores, constantemente em antagonismo com as primeiras. Nosso corpo e nossos membros são pesados assim como os halteres, barras, maças e outros aparelhos portáteis dos quais nós nos servimos para aumentar nossos esforços. Este peso se constitui em uma força a vencer ou a equilibrar, ele é exercido sempre na posição vertical. Para mudar a direção desta ação é necessário se utilizar de máquinas a contrapeso, de molas e de oposições. (Fig.1) (DEMENY, 1904b, p. 1-2)

Figura 1 - Desenhos de Demeny

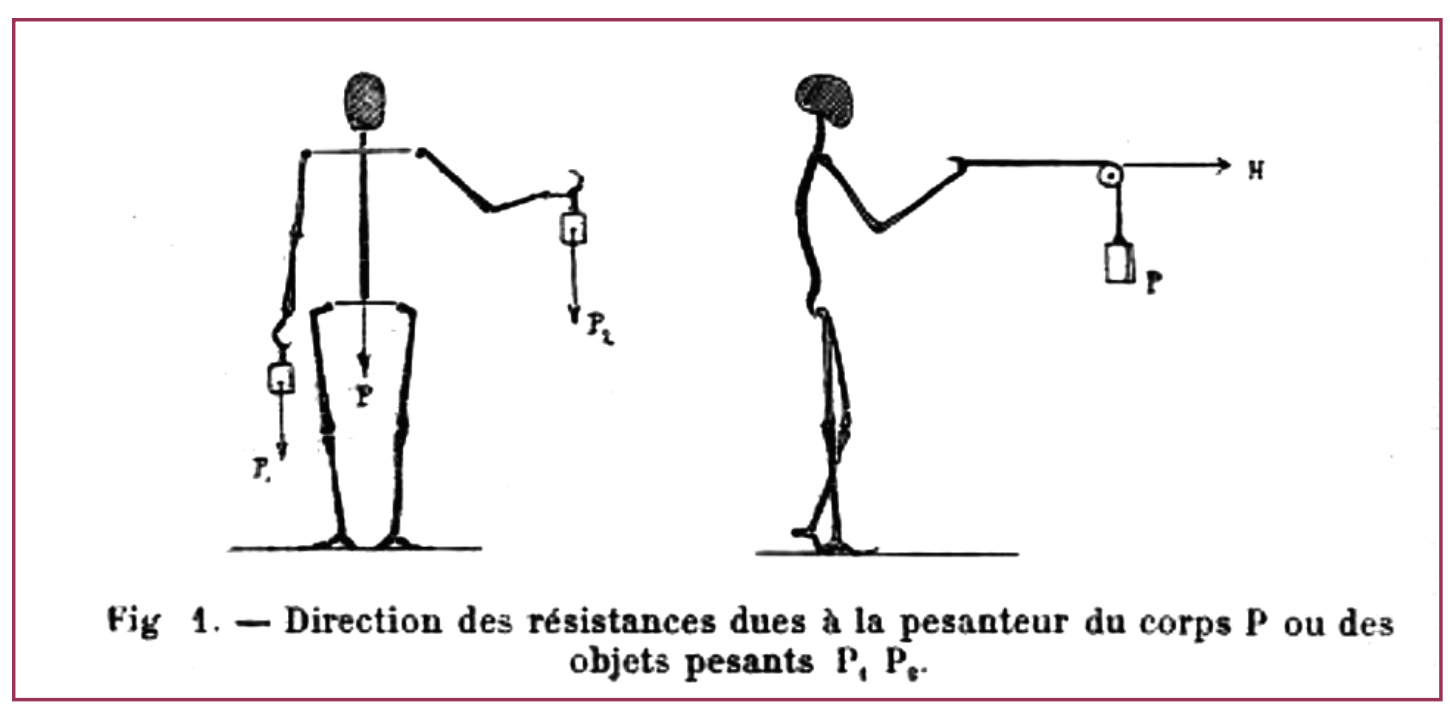

Fonte: DEMENY, 1904b, p. 2.

A máquina humana contava com uma instrumentalização dos exercícios a partir de dispositivos portáteis concebidos como uma tecnologia do treinamento. 0 corpo-máquina em interação com forças externas potencializadas por instrumentos e objetos afastava os homens de uma relação intuitiva com o movimento para aproximá-lo de conhecimentos sistematizados e organizados dentro de uma lógica mecânica de cálculo preciso. Halteres, pesos e barras eram extensões do próprio corpo que tornavam os exercícios mais eficientes. Dessa forma, Demeny contribuiu para a construção de uma representação que, nas suas palavras, aludia a uma ginástica mais verdadeira, científica, enfim, o resultado de uma evolução que naqueles tempos significava o nascimento de uma "verdadeira Educação Física". Era a finitude do projeto de sua vida, conceber a verdadeira Educação Física. Para isso, muitas escolhas foram feitas, outras práticas e discursos foram colocados como ultrapassados, anacrônicos. Afinal para ratificar essa posição, do corpo-máquina, da Educação Física científica, não era suficiente relacionar os corpos com a física e a matemática, era preciso usar a história para situar-se como a vanguarda, estabelecendo fases anteriores, onde sua representação era o desfecho de uma trajetória linear no tempo. No livro Evolution de l'éducation physique: L'école française, de 1909, Demeny, depois de trinta anos de carreira na área da ginástica, decide contar essa história, destacando a Educação Física francesa:

A reforma de nossa educação física não deve ser um malogro. Aumentemos nossos recursos completando assim nossas lacunas, mas não façamos uma troca que possa apresentar desvantagens, nem uma ação descuidada pelo simples prazer de mudar. 
Nós repetimos à exaustão o nome de Ling, mas ignoramos o nome daqueles que 0 antecederam, nós esquecemos os esforços que foram feitos entre nós e os trabalhos notáveis que prepararam o terreno para a verdadeira educação fisica cientifica e francesa. É uma injustiça gritante, é um dever para nós repará-la (DEMENY, 1909, p.8)

Neste livro, Demeny cria uma periodização, descrevendo três fases de evolução da Educação Física. A primeira seria a empírica, sem base científica, identificava-se desde as influências gregas e romanas da Antiguidade até meados do século XX, com as proposições de Francisco Amóros, Eugène Paz, Napoléon Laisné. A segunda fase ele intitulou de "tâtonnements", uma fase intermediária entre o empirismo e o pensamento científico, caracterizada pela tentativa e erro, e por lentos progressos no entendimento dos exercícios físicos. Nesta fase, Demeny destaca a ginástica sueca, concebendo-a como uma ginástica pré-científica. Em seus termos:

Novos adeptos receberam a missão, não se sabe muito bem ao certo por que, de introduzir o sistema sueco entre nós, com a ideia absoluta e imutável de nos impô-lo, sem responder aos nossos argumentos, com seus dogmas e seus erros. Podemos aceitar uma tal maneira de proceder? Se o sistema sueco é verdadeiramente científico, é facil constatá-lo servindo-se dos procedimentos da ciência moderna, seus resultados não são tangíveis e mensuráveis? (DEMENY, 1909, p. 121).

$\mathrm{Na}$ terceira e última fase, intitulada "fase positiva" [phase positive], Demeny elege a Educação Física positiva como a prática de ginástica verdadeiramente científica. Logicamente, os princípios que ele defendia, como economia das energias e eficiência dos exercícios, estavam presentes na Educação Física positiva. Com base em fichas individuais, aquela ginástica sustentava-se na experimentação, dando cientificidade a sua pedagogia. No embate entre diferentes tradições e proposições de ginástica, Demeny colocava-se como representante da ciência experimental, desse modo, julgava seu método mais verdadeiro, a última etapa na história da evolução da Educação Física. Considerava que somente a sua proposição tinha base fisiológica e mecânica para compreender que:

A Educação física é necessária; ela faz parte da educação geral; ela é inseparável da educação moral e da educação intelectual. Ela não consiste em buscar a força atlética nem vencer as dificuldades excepcionais imaginadas sem razão; ela ensina o homem a dar seu máximo de rendimento num trabalho útil, com o mínimo de dispêndio e fadiga (DEMENY, 1909, p. 279).

Como expressão de um pensamento científico, a ginástica concebida e metodizada por Demeny produzia um discurso que excluía práticas corporais que escapassem ao seu desenho. Produtora de um corpo racional, talvez próximo de uma concepção de corpo-máquina ainda em voga, essa ginástica estaria sintonizada com ideais de nação em que a luta pela vida e pela pátria por meio do exército e do trabalho é que nutrem e solidificam o corpo social. É nesse quadro que se pode afirmar que a racionalidade dos exercícios corporais trazia em seu interior um forte caráter moral, pois o corpo é em primeira instância o lugar dos limites morais, é por meio da gestualidade humana que conhecemos os limites de moralidade de uma sociedade (SOARES, 1998, VIGARELLO, 2001).

\section{CONSIDERAÇÕES FINAIS}

A construção da mentalidade do corpo-máquina teve suas representações em discursos e práticas científicas. Na longa duração observamos a permanência da metáfora do corpo como 
instrumento, como matéria, sem subjetividade, como res extensa. Mas isto não significa uma uniformidade, pois cada discurso produziu representações que convergiam e divergiam sobre 0 corpo. Contudo, a modernidade reforçou a metáfora do corpo-máquina através da ciência e de uma estética realista. $O$ século XIX trouxe novas tecnologias e possibilidades de observação dos corpos e, com elas, novas práticas foram disseminadas e confrontadas, usando, por sua vez, o argumento de autoridade da ciência.

Para Denise Sant'Anna (2001), desde o século XVI cada corpo tende a ser considerado uma máquina. A partir do século XVIII, e principalmente no século XIX, o entendimento desta máquina ganha uma complexidade inédita, despertando em médicos e educadores 0 interesse em transformá-lo cotidianamente por meio da ciência, que, sem dúvida, também sistematizou a ginástica sob seus parâmetros desde fins desse século. A ginástica racional e científica colocava-se como resultado de uma evolução, pois, para Demeny, estava atrelada ao pensamento positivo, e tinha como méritos a objetividade e a superação de práticas corporais sem controle, sem base teórica, influenciadas ainda pela "tentativa e erro".

Ecos dos discursos oitocentistas de cientificidade do corpo são fortemente notados atualmente. Reduto de objetividade, o corpo tende a ser descrito e analisado, majoritariamente, pela lógica do experimento, pelo resultado de uma performance traduzida em números e percentis, numa clara tentativa de reduzir possibilidades narrativas e análises científicas mais amplas. Ao contrário, talvez fosse necessário o esforço de narrar essa materialidade feita de carnes e de entranhas, desde uma leitura de sua ambiguidade, ao mesmo tempo material e imaterial, constituída de subjetividade. Nesse movimento do pensamento, talvez fosse importante lembrar que sua anatomia é também histórica e que o desenho desse corpo disposto para a ciência, se remetido à história e à cultura, fornecerá outras informações.

\section{REFERÊNCIAS}

BAKER, Richard. The history of gait analysis before the advent of modern computers. Gait and Posture, Oxford, v. 26, n. 3, p. 331-342, 2007.

BERNARD, Claude. Introduction a l'étude de la médecine experimentale. Paris: J. B. Baillière et Fils, 1865. Disponível em <http://www.acgrenoble.fr/PhiloSophie/file/bernard_ medecine_exp.pdf>. Acesso em: 21 dez. 2013.

BERNARD, Claude. La science expérimentale. Paris: J.B. Baillière, 1878.

BERNARD, Claude. Rapports sur les progrès et la marche de la physiologie générale en France. Paris: Imprimerie impériale, 1867.

BLOCH, Marc. Apologia da história ou o ofício de historiador. Rio de Janeiro: Zahar, 2001.

BLOCH, Marc. Introdução à história. 2. ed. Mira-Sintra: Europa-América, 2010.

BLOCH, Marc. A sociedade feudal. Lisboa: Edições 70, 1987.

CAPONI, Gustavo. Claude Bernard y los límites de la fisiología experimental. História,

Ciências, Saúde - Manguinhos, Rio de Janeiro, v. 8, n. 2, p. 375-406, jul./ago. 2001. 
CAMUS, Albert. Essais. Paris: Gallimard, 1965.

DEMENY, Georges. Les bases scientifiques de l'éducation physique. 8. ed. Paris: F. Alcan, 1931.

DEMENY, Georges. Evolution de l'éducation physique: l'ecole française. Paris: Fournier, 1909.

DEMENY, Georges. Guide du maitre: chargé de l'enseignement des exercices physiques dans les écoles. 3. ed. Paris: F. R. De Rudeval, 1904a.

DEMENY, Georges. Mécanisme et éducation des mouvements. Paris: F. Alcan, 1904b.

ELIAS, Norbert. 0 processo civilizador: formação do estado e civilização. 2. ed. Rio de Janeiro: Zahar, 1995. v. 2.

ELIAS, Norbert. 0 processo civilizador: uma história dos costumes. 2. ed. Rio de Janeiro: Zahar, 1994. v. 1.

FOUCAULT, Michel. Os anormais. São Paulo: Martins Fontes, 2003.

FOUCAULT, Michel. História da sexualidade. Rio de Janeiro, Graal, 1998. v. 3.

FOUCAULT, Michel. Microfísica do poder. 6. ed. Rio de Janeiro: Graal, 1980.

FOUCAULT, Michel. Nascimento da biopolítica. São Paulo: Martins Fontes, 2008.

GLEYSE, Jacques et al. Physical Education as a Subject in France (School Curriculum, Policies and Discourse): The Body and the Metaphors of the Engine-Elements. Used in the Analysis of a Power and Control System during the Second Industrial Revolution. Sport, Education and Society, London, v. 7, n. 1, p. 5-23, 2002.

GOELLNER, Silvana Vilodre. O método francês e a militarização da educação física na escola brasileira. In: FERREIRA NETO, A. Pesquisa histórica na educação física brasileira. Vitória: UFES, 1996. p. 123-143.

MAUSS, M. Les techniques du corps.Journal de Psychologie, Paris, v. 32, p. 1-23, mar. 1936. Disponível em: <http://www.reginedetambel.com/images/30/revue 1844.pdf >. Acesso em: 24 jun. 2013.

MELO, V. A. A presença do esporte no cinema: de Étienne-Jules Marey a Leni Riefenstahl. Revista Brasileira de Educação Física e Esporte, São Paulo, v. 19, n. 2, p. 115-125, abr./jun. 2005.

RABINBACH, Anson. The human motor: fatigue, energies and the origins of modernity. Los Angeles: University of California Press, 1992.

SANT'ANNA, Denise Bernuzzi de. La recherche de la beauté. 1994. 658 f. Thèse (Doctorat) Histoire, Université Paris Diderot - 7, Paris, 1994. 2 v.

SANT'ANNA, Denise Bernuzzi de. Educação Física e história. In: CARVALHO, Y.; RUBIO, K., (Org.). Educação física e ciências humanas. São Paulo: Hucitec, 2001. p. 48-66.

SHELLEY, Mary W. Frankenstein; or, the modern Prometheus. Cambrigde: Server, Francis, 1869. 
SOARES, Carmen Lúcia. Imagens da educação no corpo: estudo a partir da ginástica francesa no século XIX. 1996. 119 f. Tese (Doutorado) - Educação, Universidade Estadual de Campinas, Campinas, 1996.

SOARES, Carmen Lúcia. Imagens da educação no corpo: estudo a partir da ginástica francesa no século XIX. Campinas: Autores Associados, 1998.

SOARES, Carmen Lúcia; FRAGA, Alex Branco. Pedagogia dos corpos retos: das morfologias disformes às carnes humanas alinhadas. Pro-posições, Campinas, v. 14, n. 2, p. 77-90, maio 2003.

TERRA, Vinícius Demarchi Silva. Memórias anatômicas. 2007. 167 f.Tese (Doutorado) Educação, Universidade Estadual de Campinas, Campinas, 2007.

TERRA, Vinícius Demarchi Silva. Pedaços do tempo, gestos partidos: memórias do corpo em movimento na fotografia de Étienne-Jules Marey. 2002. 133 f. Dissertação (Mestrado) Educação, Universidade Estadual de Campinas, Campinas, 2002.

VIGARELLO, Georges. A invenção da Ginástica no século XIX: movimentos novos, corpos novos. Revista Brasileira de Ciências do Esporte, Campinas, v. 25, n. 1, p. 9-20, set. 2003.

VIGARELLO, Georges. Du jeu ancien au show sportif: la naissence d'um mythe. Paris: Seuil, 2000.

VIGARELLO, Georges. Lês corps rédresse: histoire d'um pouvoir pédagogique. Paris: Armand Colin, 2001.

VIGARELLO, Georges. 0 limpo e o sujo: a higiene do corpo desde a idade média. Lisboa: Fragmentos, 1985.

VIGARELLO, Georges; HOLT, Richard. O corpo trabalhado: ginastas e esportistas no século XIX. In: CORBIN, A; COURTINE, J.; VIGARELLO, G. História do corpo. Rio de Janeiro: Vozes, 2008. v. 2, p. 393-478.

WHEWELL, William. The philosophy of the inductive sciences: founded upon their history. London: John W. Parker, 1860. v. 1.

Apoio: esta pesquisa contou com o apoio financeiro da FAPESP, Projeto Regular de Pesquisa, Processo n.2013/15043-7; e do CNPq, Bolsa de Produtividade em Pesquisa. 